\section{THU0129 CD8+CD28- T-LYMPHOCYTES ARE ASSOCIATED WITH SUBCLINICAL ATHEROSCLEROSIS IN PATIENTS WITH RHEUMATOID ARTHRITIS}

B. Wahlin ${ }^{1}$, A.E. Fasth ${ }^{2}$, K. Karp ${ }^{3}$, K. Lejon ${ }^{4}$, A. Södergren ${ }^{1}$, S. Wållberg-Jonsson ${ }^{1} .{ }^{1}$ Public health and clinical medicine/Rheumatology, Umeå university, Umeå, Umeå; ${ }^{2}$ Rheumatology Unit, Department of Medicine at Solna, Karolinska institutet, Stockholm; ${ }^{3}$ Surgical and Perioperative Sciences; ${ }^{4}$ Clinical Microbiology, Immunology, Umeå university, Umeå, Umeå, Sweden

Background: Patients with rheumatoid arthritis (RA) have an increased mortality and morbidity due to cardiovascular disease and accelerated progression of atherosclerosis. Altered populations of T-lymphocytes are associated with atherosclerosis, and chronic infection with cytomegalovirus (CMV) affects the T-cell-population.

Objectives: To study the association between subsets of T-lymphocytes, subclinical atherosclerosis assessed by intima-media thickness (IMT) and antibodies against CMV in patients with RA.

Methods: Patients with new-onset RA ( $n=71)$, aged $<60$ years at diagnosis, were consecutively included in a study of development of atherosclerosis. Ultrasound measurement of IMT of a. carotis communis was undertaken at inclusion (T0), after five years (T5) and after 11 years $(T 11)(n=54)$. At T11, flow-cytometry was undertaken to investigate subsets of T-lymphocytes (CD45+CD3+), where CD4, CD8, CD28, CD56 and CX3CR1 was studied. CX3CR1 is the ligand of fractalkine, an adhesion molecule expressed on activated endothelial cells to attract leukocytes. Serological analysis for CMV was undertaken from samples collected at T0, T5 and T11.

Results: The percentage of CD8+T-lymphocytes lacking the co-stimulatory molecule CD28 (CD8+CD28-) was significantly (standardized beta coefficient 0.39 , p-value 0.01) associated with IMT at T11 in a linear regression model including T0 variables smoking, systolic blood pressure and cholesterol. No association with IMT was seen for CD4+CD28- T-lymphocytes. CX3CR1 was expressed in $71 \%$ of CD8+CD28- T-lymphocytes, compared with $8.2 \%$ of CD8+CD28+. The prevalence of immunoglobulin G seropositivity for CMV was $47 / 70$ (67\%), 42/66 (57\%) and 34/56 (52\%) at T0, T5 and T11 respectively. Patients with constantly positive CMV serologies (T0, T5 and T11) had a significantly higher percentage of CD8+CD28- and CD4+CD28- T-lymphocytes. Also the proportion of cells expressing CX3CR1 was in both CD4+ and CD8+ T-lymphocytes associated with constantly positive serologies for CMV.

Conclusions:

Subclinical atherosclerosis in patients with RA was associated with CD8+CD28T-lymphocytes in a regression model adjusted for traditional cardiovascular risk factors. Positive serologies for CMV were associated with an increased proportion of CD8+CD28- T-lymphocytes and T-lymphocytes expressing CX3CR1.

Disclosure of Interest: B. Wahlin: None declared, A. Fasth Employee of: Novartis Sweden AB, K. Karp: None declared, K. Lejon: None declared, A. Södergren: None declared, S. Wållberg-Jonsson: None declared

DOI: 10.1136/annrheumdis-2017-eular.4364

\section{THU0130 IMPROVEMENT IN MEASURES OF DEPRESSED MOOD AND ANHEDONIA IN TWO RANDOMIZED, PLACEBO-CONTROLLED PHASE III STUDIES OF SIRUKUMAB, A HUMAN ANTI-INTERLEUKIN-6 ANTIBODY, IN PATIENTS WITH RHEUMATOID ARTHRITIS}

Y. Sun ${ }^{1}$, B. $\mathrm{Hsu}^{2}$, D. Wang ${ }^{3}$, M. Curran ${ }^{2}$, W.C. Drevets ${ }^{1}$, G. Chen ${ }^{4}$ G.M. Wittenberg ${ }^{1}$. ${ }^{1}$ Janssen Research \& Development, LLC, Titusville; ${ }^{2}$ Janssen Research \& Development, LLC, Spring House, Pa: ${ }^{3}$ Janssen Research \& Development, LLC, Raritan; ${ }^{4}$ Janssen Research \& Development, LLC, la Jolla, United States

Background: Interleukin-6 (IL-6) is one of the known neuroactive-cytokines involved in neuronal plasticity and stress coping and is associated with depression. Depressive symptoms are common in patients with rheumatoid arthritis (RA), a disease characterized by high peripheral IL-6. Previous analysis of a Phase II study ${ }^{1}$ showed that sirukumab, a human monoclonal antibody that selectively binds to the IL-6 cytokine with high affinity, can help reduce depressive symptoms in RA patients.

Objectives: To further assess and validate the effects of sirukumab on relieving depressive symptoms in RA patients.

Methods: We conducted a post-hoc analysis of 2 Phase III, randomized, doubleblind, placebo-controlled trials evaluating efficacy and safety of sirukumab in the treatment of RA. SIRROUND-D enrolled patients with active RA despite disease-modifying anti-rheumatic drugs and having serum C-reactive protein (CRP) $\geq 8 \mathrm{mg} / \mathrm{L}$ at baseline. SIRROUND-T enrolled patients with active RA despite anti-TNF therapy and having serum $\mathrm{CRP} \geq 8 \mathrm{mg} / \mathrm{L}$ or erythrocyte sedimentation rate $>28 \mathrm{~mm} / \mathrm{h}$ at baseline. Patients using antidepressants were excluded from the analysis. Patients were grouped by presence/absence of prevalent depressed mood and anhedonia (PDMA), based on the self-reported frequencies of these 2 core depressive symptoms in the SF-36, requiring one present at least "most of the time" and the other "some of the time" in the past 4 weeks. A depression score was derived based on the 2 core depressive symptoms of SF-36. Relief of depressive symptoms in patients with PDMA was evaluated by comparing changes in the depression score from baseline to week 8 between the placebo and combined sirukumab groups directly and with adjustment for RA activity as measured by the Disease Activity Score- 28 with CRP. Changes in depression score were also analyzed in RA patients who did not have an ACR50 response to sirukumab. The combined effect of anti-IL-6 treatment was estimated using meta-analysis of 2 Phase III, 1 Phase II studies of sirukumab and 1 Phase II study of the anti-IL- 6 cytokine antibody siltuximab.

Results: At baseline, $19 \%$ and $22 \%$ of patients were classified as PDMA in the 2 studies, respectively. Sirukumab treatment, compared to placebo, significantly improved depressive symptoms by week 8 among PDMA patients $(p=0.022$ and 0.046 for the 2 studies, respectively) before adjusting for changes in RA activity. Within the sirukumab group, the reduction in depressive symptoms remained significant after adjusting for changes in RA activity $(p<0.0001)$ and in ACR50 non-responders at week $8(p<0.0001)$, while differences in improvements between the sirukumab and placebo group reduced to trends. Meta-analysis of 4 anti-IL- 6 studies (1 siltuximab, 3 sirukumab) revealed that anti-IL- 6 treatment helps alleviate depressive symptoms even after adjusting for changes in disease activity (Standardized Mean Difference $=0.25, p=0.03$ )

Conclusions: Our findings are consistent with previous results from a phase II RA study. Peripheral anti-IL-6 cytokine treatment is associated with improvement in depressive symptoms in RA patients, possibly supporting a role for IL-6 dysfunction in depression.

References:

[1] Ann Rheum Dis2015;74(Suppl2): 720

Disclosure of Interest: $Y$. Sun Shareholder of: Johnson \& Johnson, Employee of: Janssen Research \& Develoment, LLC, B. Hsu Shareholder of: Johnson \& Johnson, Employee of: Janssen Research \& Develoment, LLC, D. Wang Shareholder of: Johnson \& Johnson, Employee of: Janssen Research \& Develoment, LLC, M. Curran Shareholder of: Johnson \& Johnson, Employee of: Janssen Research \& Develoment, LLC, W. Drevets: None declared, G. Chen: None declared, G. Wittenberg: None declared

DOI: 10.1136/annrheumdis-2017-eular.3263

\section{THU0131 PREMATURE CORONARY HEART DISEASE FREQUENCY IN RHEUMATOID ARTHRITIS WHO ARE RECEIVING BIOLOGIC AGENTS: HUR-BIO REAL LIFE RESULTS}

B. Armagan ${ }^{1}$, A. Sari ${ }^{1}$, A. Erden ${ }^{1}$, L. Kilic ${ }^{1}$, E.C. Erdat ${ }^{2}$, O. Karadag ${ }^{1}$, A. Akdogan $^{1}$, S. Apras Bilgen ${ }^{1}$, U. Kalyoncu ${ }^{1}$, S. Kiraz ${ }^{1}$, I. Ertenli ${ }^{1} .{ }^{1}$ Hacettepe University, Department of Internal Medicine, Division of Rheumatology; ${ }^{2}$ Hacettepe University, Department of Internal Medicine, Hacettepe University, Ankara, Turkey

Background: Patients with rheumatoid arthritis (RA) are at increased risk of coronary heart disease (CHD) overall, as well as death from $\mathrm{CHD}$. A direct impact of chronic inflamation on the vascular system, secondary effects of physical inactivity and some drugs used in the management of RA are shown as the reasons for the increase in this comorbidity (1).

Objectives: We aim to determine the frequency of $\mathrm{CHD}$ in the RA patients who receive biological agents.

Methods: Hacettepe University Biologic Registry (HUR-BIO) includes demographic and clinical data of patients treated with biological agent since 2005. By August 2016, 1235 RA patients were recorded in the database. Age, smoking status, comorbidities, current and previous treatments were analysed in 1000 patients. Disease activity was estimated by the 28-joint activity calculator (DAS28ESR) and DAS28-CRP. Functional assesment was evaluated by the Health Assessment Questionnaire (HAQ). Premature CHD should be defined if clinical $\mathrm{CHD}$ or sudden death is documented in male younger than 55 years of age and in female younger than 65 years of age.

Results: Overall 1000 patients $(79,8 \%$ female) were enrolled in this study. Mean age was $53,1 \pm 12,6$ years old, mean disease duration was $12,3 \pm 9,3$ years. CHD was detected $57(5,7 \%)$ patients and female/male was 38/19. Premature CHD was observed in $38(66,7 \%)$ patients. CHD patients had more frequently male, older, higher classical risk factors, higher baseline ESR level and higher functional disability (Table). HAQ score also remained high in CHD group at last visit. Classical cardiovascular risk factors, sex, seropositivity, disease activity score and $\mathrm{HAQ}$ score were similar in the premature and other CHD group. Coronary artery stenting, coronary artery bypass surgery and medical treatment was applied in $12(21 \%), 20(35,1 \%)$ and $25(43,9 \%)$ CHD patients, respectively. There was no statistical difference in treatment of premature and other $\mathrm{CHD}$.

Table 1. Characteristic of patients who have CHD or not

\begin{tabular}{lccc}
\hline & $\mathrm{CHD}(\mathrm{n}=57)$ & No CHD $(\mathrm{n}=943)$ & $\mathrm{p}$ \\
\hline Female $\mathrm{n}(\%)$ & $38(66,6)$ & $19(80,6)$ & 0,011 \\
Hypertansion $\mathrm{n}(\%)$ & $38(66,6)$ & $271(28,7)$ & $<0.001$ \\
Diabetes Mellitus $\mathrm{n}(\%)$ & $11(19,3)$ & $97(10,3)$ & 0.033 \\
Smoking (current/past) $\mathrm{n}(\%)$ & $30(52,6)$ & $370(39,2)$ & 0.003 \\
Age mean (SD) & $64,7(9,9)$ & $52,4(12,4)$ & $<0.001$ \\
Baseline Erythrocyte sedimentation rate (SD) & $45,7(30,3)$ & $36,1(24,6)$ & 0.009 \\
Baseline HAQ mean (SD) & $1,27(0,64)$ & $1,02(0,62)$ & 0.025 \\
Last HAQ mean (SD) & $0,84(0,64)$ & $0,66(0,58)$ & 0.024 \\
\hline
\end{tabular}

CHD: Coronary heart disease, HAQ: Health Assessment Questionnaire.

Conclusions: As a results CHD were detected in 5,7 percents of RA patients who are receiving biological agents. Importantly, two third of these patients have 